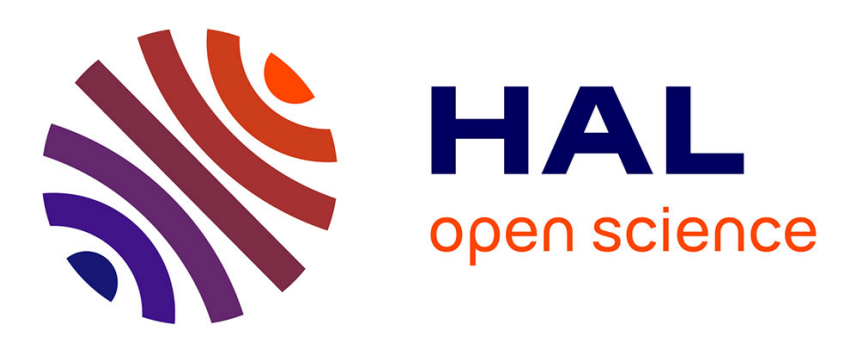

\title{
Correlation between optical properties surface morphology of porous silicon electrodeposited by Fe3+ ion
}

Asma Mabrouk, Nathalie Lorrain, Lazhar Mohamed Haji, Maherzi Oueslati

\section{- To cite this version:}

Asma Mabrouk, Nathalie Lorrain, Lazhar Mohamed Haji, Maherzi Oueslati. Correlation between optical properties surface morphology of porous silicon electrodeposited by Fe3+ ion. Superlattices and Microstructures, 2015, 77, pp.219-231. 10.1016/j.spmi.2014.10.028 . hal-01095824

\section{HAL Id: hal-01095824 \\ https://hal.science/hal-01095824}

Submitted on 6 Jan 2015

HAL is a multi-disciplinary open access archive for the deposit and dissemination of scientific research documents, whether they are published or not. The documents may come from teaching and research institutions in France or abroad, or from public or private research centers.
L'archive ouverte pluridisciplinaire HAL, est destinée au dépôt et à la diffusion de documents scientifiques de niveau recherche, publiés ou non, émanant des établissements d'enseignement et de recherche français ou étrangers, des laboratoires publics ou privés. 


\title{
Correlation between optical properties surface morphology of porous silicon electrodeposited by $\mathrm{Fe}^{3+}$ ion
}

\author{
A. Mabrouk ${ }^{1, *}$, N. Lorrain ${ }^{2}$, M. L. Haji ${ }^{2}$ and M. Oueslati ${ }^{1}$ \\ 1 Unité de Nanomatériaux et Photonique, Faculté des Sciences de Tunis, Département de Physique,2092 El \\ Manar, Tunis - Tunisia \\ 2 Université Européenne de Bretagne, CNRS FOTON-UMR 6082, 6 rue de Kérampont, BP 80518,22305 \\ Lannion Cedex, France. \\ * Corresponding author: asmamabrouk@gmail.com
}

\begin{abstract}
In this paper, we analyze the photoluminescence spectra (PL) of porous silicon (PS) layer which is elaborated by electrochemical etching and passivated by $\mathrm{Fe}^{3+}$ ions (PSF) via current density, electro-deposition and temperature measurements. We observe unusual surface morphology of PSF surface and anomalous emission behavior. The PSF surface shows regular distribution of cracks, leaving isolated regions or "platelets" of nearly uniform thickness. These cracks become more pronounced for high current densities. The temperature dependence of the PL peak energy $\left(\mathrm{E}_{\mathrm{PL}}\right)$ presents anomalous behaviors ,i.e., the PL peak energy shows a successive red/blue/redshift (S-shaped behavior) with increasing temperature that we attribute to the existence of strong potential fluctuations induced by the electrochemical etching of PS layers. A competition process between localized and delocalized excitons is used to discuss these PL properties. In this case, the potential confinement plays a key role on the enhancement of PL intensity in PSF. To explain the temperature dependence of the PL intensity, we have proposed a recombination model based on the tunneling and dissociation of excitons.
\end{abstract}

Keywords: Silicon, Nanocristallites, Radiative recombination, Potential fluctuations. 


\section{Introduction}

In recent years, Porous silicon (PS) layer has been intensively investigated due to its strong photoluminescence (PL) properties in the visible range [1] at room temperature.

For its large surface area and high chemical reactivity, PS is also considered as a promising material for different applications such as photovoltaic conversion [2,3], silicon-insulator (SOI) $[4,5]$ and sensor technologies[6,7]. However, the inefficiency and instability $[8,9,10]$ of the optical properties of the PS create many problems in the application area such as the decrease of PL intensity $[9,10]$ and the shift of the energy of maximum of PL band $[9,10]$ due to the surface oxidation of PS crystallites. To solve this problem, new nano-composites lines have been developed by the insertion of atomic or molecular species such as hydrocarbons, polymers, semiconductors and transition metals [11-15]. Herino et al [16] investigated the deposition of metals and other conducting materials in relation to their influence on the luminescent properties of PS and to their modification of its conductivity. The metal incorporation has been carried out by electrochemical or electroless methods and also by evaporation and revealed an increase of the electroluminescence after the deposition of In and $\mathrm{Al}$ into porous silicon. Galvanostatic and electroless deposition of $\mathrm{Au}, \mathrm{Ni}$ and $\mathrm{Cu}$ has been used and it is accompanied by an oxidation of the porous silicon surface whereas cathodic deposition does not generate oxide formation at the pore surface [17]. Silicon dots have been also obtained using liquid and vapor phase preparation methods, which the formation has been evidenced using SEM (Scanning Electron Microscopy) and AFM (Atomic Force Microscopy) [18, 19].

Electro-deposition of $\mathrm{Au}, \mathrm{Pt}$ and Pd into macro-pores has been studied [20, 21]. It has shown that macro-porous silicon filling with Pd and Pt starts growing from the pore bottom. On the other hand, for the deposition of Au, no condition could be found to achieve this behavior. The deposition is performed under cathodic conditions by choosing an appropriate supporting electrolyte which induces a shift of the open-circuit potential to negative values and inhibits oxidation of the silicon. Since the equilibrium potential of $\mathrm{Au}$ is more positive compared with $\mathrm{Pt}$ and $\mathrm{Pd}$, the rate of hole injection is faster and this is the result of the greater difference between the equilibrium potential and the silicon valence band.

Even if the electro-deposition process is well described in the literature $[16,17,20,21]$, the physical properties of the obtained compound depend on fixed parameters of the sample preparation including the chemical nature of the semiconductor, crystal orientation, doping type and density, electrolyte composition and applied current or voltage. Systematic investigations with different electro-deposition parameters are required in order to find new and better physical properties. Iron has been successfully used to stabilize PS layers and 
interesting results has been obtained [22]. Direct impregnation of SP in $\mathrm{Fe}\left(\mathrm{NO}_{3}\right)_{3}$ solution [22] has been used to showed an improvement and stabilization of PS photoluminescence (PL) after only three weeks. Rahmani et al. [22] demonstrated by EDX analysis that atomic percentage of iron has decreased from the top to the bottom of the layer indicating that iron deposition occurs mainly at the pore bottom. Rahmani et al attributed this stability of the PL to the passivation of the Si nano-crystallites by iron. Beside, a gradient of the metal content towards the pore tips has been observed by Ronkel et al. [17]. Fe-deposition into the pores carried out to achieve electrical contact to porous silicon starts with the nucleation at the pore bottom because of the cathodic standard potential of Fe that is close to the one of silicon [17].

In the present work, the filling of porous silicon matrices with iron nanostructures is carried out electrochemically in a second process step after the anodization of the silicon wafer. Here we report the influence of iron electro-deposition parameters including iron concentration and current density on optical and morphological properties of PS electropassivated by iron ions (PSF). The correlation of the optical and morphological properties of samples has been investigated using photoluminescence study.

\section{Experimental details}

An ohmic contact was first formed by coating the backside of the silicon wafer with aluminum (Al) and subsequently annealed at $300^{\circ} \mathrm{C}$ for $30 \mathrm{~min}$. PS layer was created from boron-doped p-type $\operatorname{Si}(100)$ substrate by electrochemical etching in 2:1:1 of $40 \%$ hydrofluoric acid, ethanol and water mixture with a current density of $10 \mathrm{~mA} / \mathrm{cm}^{2}$ for 6 minutes. After anodization process, the samples were rinsed in pure water and dried by argon gas. The electro-deposition of iron was carried out in an aqueous electrolyte containing $\mathrm{FeCl}_{3}(0.3 \mathrm{M})$ for15 min at different current densities and was followed by drying with argon gas to remove residual impurities. Five samples PSF3, PSF11, PSF22, PSF28 and PSF32 have been prepared for the following electro-deposition current densities $\mathrm{J}_{\mathrm{c}}=3 \mu \mathrm{A} / \mathrm{cm}^{2}, \quad \mathrm{~J}_{\mathrm{c}}=11 \mu \mathrm{A} / \mathrm{cm}^{2}$, $\mathrm{J}_{\mathrm{c}}=22 \mu \mathrm{A} / \mathrm{cm}^{2}, \mathrm{~J}_{\mathrm{c}}=28 \mu \mathrm{A} / \mathrm{cm}^{2}$ and $\mathrm{J}_{\mathrm{c}}=32 \mu \mathrm{A} / \mathrm{cm}^{2}$.

Structural and morphological qualities of both PS and PSF samples prepared for different current densities were investigated by scanning electron microscope (SEM) (JEOL JSM -5600 LV equipped with X-ray (EDX) spectrometer used for compositional investigation on the cross-section of the samples. The minimum iron concentration which can be detected is about $0.1 \mathrm{at} \%$. The estimated error for each concentration variation was at most $0.3 \%$ taking into account the doping inhomogeneity of the sample. The scanned surface is about $1 \mu \mathrm{m}^{2}$ with a resolution of $1 \mu \mathrm{m}$. 
PL measurements were carried out in a variable temperature $(10-300 \mathrm{~K})$ closed-cycle cryostat with Jobin-Yvon T64000 spectrometer. We used the $488 \mathrm{~nm}$ wavelength of spectra Physics 2017 argon laser and an incident laser power of $5 \mathrm{~mW}$ at the surface of the sample. The Raman shift was determined with an accuracy of $0.25 \mathrm{~cm}^{-1}$ (1800 gr/mm grating mode).

\section{Results and discussions}

\subsection{Characterization of porous silicon/iron composites by SEM and EDX}

SEM images of the surface were taken before (PS as prepared sample) and after iron electro-deposition (PSF3 and PSF22 samples) in order to study the evolution of the surface morphology (Fig. 1). After Fe ion electro-deposition, regular cracks were formed leaving isolated regions or "platelets" of nearly uniform thickness. These cracks become more pronounced for relative high current densities $J_{c}$ (Fig. 1C) and disappear for very high $J_{c}$ (Fig. 1D) due to the increase of the corrosive effect of the electro-deposition.

The SEM images of the cross section of samples etched with different $J_{c}$ are shown in Fig. 2 . It seems that the cracks are formed at a region of high stress that we associate to lattice defects. The presence of pores favors the formation of cracks through the structure, leaving distinctive "islands" where the porous silicon network has collapsed laterally parallel to the $\mathrm{Si}$ substrate.

The platelets or islands are loosely bound to the substrate (see Fig .2 B and C) and show slight curling around their edges for samples etched for $\mathrm{J}_{\mathrm{c}} \leq 22 \mu \mathrm{A} / \mathrm{cm}^{2}$. The degree of curling increases with increasing $J_{c}$ and becomes even higher for $J_{c}=32 \mu \mathrm{A} / \mathrm{cm}^{2}$ (Fig. 2D), this effect induces an increase in diameters due to the total dissolution of Si nano-crystallites. At low current densities, pores unzip normally to the surface inducing lateral collapse of the platelets as seen in Fig.2B. The increase of $J_{c}$ would induce both lateral and normal stresses which would be responsible for the sponge structure of samples. For high $\mathrm{J}_{\mathfrak{c}}$, the formation of curled platelets proves the corrosive behavior of electro-deposition.

Complementary studies using Energy dispersive X-ray analysis were carried out to estimate the iron concentration through the depth of the porous layer. In Fig. 3, we show that Fe atomic percentage for PSF3 sample decreases from the top to the bottom of the layer. This proves that iron is well incorporated into the PS layer but the amount is not homogeneously distributed in the porous layer. By an electro-deposition method, Iron is mainly deposited in the first micrometer of the porous layer from the surface, and not at the pore bottom as in the impregnation method. 


\subsection{Photoluminescence studies}

\subsubsection{Electro-deposition current density dependence of $P L$ at $T=300 \mathrm{~K}$}

Fig. 4 shows the PL spectra of PS and PSF samples for different current density $J_{c}$. We observed an enhancement of the PL intensity $\left(\mathrm{I}_{\mathrm{PL}}\right)$ with increasing $\mathrm{J}_{\mathrm{c}}$. The $\mathrm{I}_{\mathrm{PL}}$ intensity reached a maximum for $\mathrm{J}_{\mathrm{cM}}=22 \mu \mathrm{A} / \mathrm{cm}^{2}$. For $\mathrm{J}_{\mathrm{c}} \leq \mathrm{J}_{\mathrm{cM}}$, we note a slight blue-shift of the PL band energy which we attributed to the increasing confinement in dots and wires that we attribute to the decrease of the nano-crystallite sizes [23, 24]. As we have already discussed (See Fig. 1), the pores unzip normal to the surface inducing lateral collapse of the platelet and causing a change in the pore-morphology. So, a corrosive behavior of electro-deposition occurs for high $\mathrm{J}_{\mathfrak{c}}$, leading to a complete dissolution of silicon nano-crystallites and accompanied of a decrease of the $\mathrm{I}_{\mathrm{PL}}$ (Fig. 4).

\subsubsection{PL and shape of crystallites}

It has been proven in several studies $[25,26]$ that the porous p-type layer is formed by cylindrical and spherical crystallites shapes. Thus, PS is described as a mixture of quantum dots (QD) and quantum wires (QW) of different concentrations and sizes. The theoretical PL spectra could be calculated by using a simple quantum confinement-based model [27, 28] where the visible red photoluminescence (PL) is only produced in QWs and QDs. The total PL intensity ( $\left.\mathrm{I}_{\mathrm{PL}}\right)$ of PS is the sum of contributions of wire and dot emission.

$$
\mathrm{I}_{\mathrm{PL}}=I_{W}+I_{D}
$$

Where and represent the intensity contributions of wires and dots in the PL spectra respectively and they are expressed by [27, 28]:

$$
\begin{aligned}
& I_{W}=k_{W} \chi_{W} \Delta E^{-3.16} \mathrm{X} \exp \left[-\frac{1}{2}\left(\frac{\mathrm{d}_{0 \mathrm{~W}}}{\sigma_{\mathrm{W}}}\right)^{2}\left(\frac{{ }^{c_{\mathrm{W}}}{ }^{0.72}}{\mathrm{~d}_{0 \mathrm{~W}}}\left[\Delta E_{W}\right]^{-0.72}-1\right)^{2}\right] \\
& I_{D}=k_{D} \chi_{D} \Delta E^{-3.88} \mathrm{X} \exp \left[-\frac{1}{2}\left(\frac{\mathrm{d}_{0 \mathrm{D}}}{\sigma_{\mathrm{D}}}\right)^{2}\left(\frac{\mathrm{c}_{\mathrm{D}} \mathrm{d}^{0.72}}{\mathrm{~d}_{0 \mathrm{D}}}\left[\Delta E_{D}\right]^{-0.72}-1\right)^{2}\right]
\end{aligned}
$$

$\mathrm{k}_{\mathrm{W}}$ and $\mathrm{k}_{\mathrm{D}}$ are suitable normalization constants. $\chi_{W}$ and $\chi_{D}$ are the concentrations of luminescent wires and dots, respectively, and their root mean square and. We assume a Gaussian distribution of the diameters $d_{W}$ and $d_{D}$ of the wire and the dots, centered on their mean values $d_{0 W}$ and $d_{0 D}$, respectively. We have adopted the dependence of $\left[d_{W(D)}\right]^{-1.39}[29]$ for the energy gap versus the crystallite diameter $d_{W(D)} . \Delta \mathrm{E}_{\mathrm{W}(\mathrm{D})}$ are the confinement contributions of QWs and QDs on the energy gap of the PS.

From the fitting of theoretical PL spectra to experimental ones (See Fig. 5), we have determined all the optimized fitting parameters $\chi_{W}, \chi_{D}, d_{0 W}, d_{0 D}, \sigma_{W}$ and $\sigma_{D}$ characterizing the QWs and the QDs (See Table 1). 
In Fig. 5, we present the variation of QD (QW) diameter $d_{D}\left(d_{W}\right)$ as function of electrodeposition current density $\mathrm{J}_{\mathrm{c}}$. For low $\mathrm{J}_{\mathrm{c}}$, we observe a decrease of the diameters $\mathrm{d}_{\mathrm{D}}$ and $\mathrm{d}_{\mathrm{W}}$, illustrating an etching effect of $\mathrm{Si}$ atoms and a reducing of crystallite sizes which induces a blue shift of the PL band (See Fig. 4). However, for $J_{c}$ which is relatively high $\left(28 \mu \mathrm{A} / \mathrm{cm}^{2}\right), d_{D}$ and $\mathrm{d}_{\mathrm{W}}$ do not change. This behavior is accompanied by a corrosive behavior as it has been shown by SEM images (See Fig. 1). As for the adjusting theoretical PL spectra, an increase of the PL intensity ratio $\left[\mathrm{I}_{\mathrm{PL}}(\mathrm{QW}) / \mathrm{I}_{\mathrm{PL}}(\mathrm{QD})\right]$ is first observed with electrodeposition process. This proved that the etching process reduced the sizes of both wires and dots and preferentially destroys the spheres. The reduction of the sizes induced a blue shift of the total PL band for low current density (etching mechanism) and then a decrease of PL intensity occurs for high $\mathrm{J}_{\mathrm{c}}$ due to corrosive mechanism as clearly illustrated in Fig. 4.

\subsubsection{PL temperature dependence}

In Fig. 7, we present the evolution of the PL maximum band energy $\left[E_{\mathrm{PL}}(\mathrm{T})\right]$ of samples PSF3, PSF11 and PSF22 as a function of temperature in the range [10-300K] under a constant excitation power of $300 \mathrm{~W} / \mathrm{cm}^{-2}$. The $E_{\mathrm{PL}}(\mathrm{T})$ of PSF3 and PSF11 show S-shape variation which corresponds to a red shift with increasing temperature in the range $[10-60 \mathrm{~K}]$, a blue shift in the range $[60-180 \mathrm{~K}]$ and then a red shift in the range [180 - $300 \mathrm{~K}$ ]. This S-shape behavior has already been observed by several authors [30-33] and has been attributed to localized exciton (LE) by potential fluctuations induced by random distribution of impurities, defects and alloy disorder in samples [34]. The S-shape disappears in the case of PSF22 sample where $\mathrm{E}_{\mathrm{PL}}(\mathrm{T})$ presents a temperature variation according to BoseEinstein model [35] (See Fig. 7c). In Fig. 7(a and b), the first S-shape redshift between 10 and $100 \mathrm{~K}$ is attributed to thermal relaxation of LE to absolute potential minimum [30]. With an additional increase in the temperature, the excitons are thermally delocalized and transferred to the higher-energy states (blueshift) above the mobility edge (ME) in the band-tail until reaching the conduction-band edge. With a larger increase in temperature, the thermal energy prevents the exciton localization, and the PL band follows the variation of the energy gap according to Varshni law (second redshift). Thus, the S-shaped behavior of the PL band (E $E_{P L}$ $(\mathrm{T}))$ is the signature of the competition processes between the recombination of localized and delocalized excitons. We have analyzed the S- shape using the theoretical band-tail model [36], which is given by the following equation:

$$
E_{g}(T)=E_{g 0}-\frac{\alpha T^{2}}{\beta+T}-\frac{\sigma^{2}}{K_{B} T}
$$

$\mathrm{E}_{\mathrm{g}}(\mathrm{T})$ plays the role of the optic gap depending on temperature $\mathrm{T} . \mathrm{E}_{\mathrm{g} 0}$ is $\mathrm{E}_{\mathrm{g}}(\mathrm{T}=0), \alpha$ and $\beta$ the Varshni coefficients [37, 38], and $K_{B}$ the Boltzmann constant $\left(K_{B}=8.617332410^{-5} \mathrm{eV} \cdot \mathrm{k}^{-1}\right)$. 
The third term comes from the localization effect in which $\sigma$ indicates the degree of localization, i.e., the large value of $\sigma$ means a strong localization effect. We present in Fig.7.a (b) the fitting of experimental values $\mathrm{E}_{\mathrm{g}}(\mathrm{T})$ using the equation (4) for PSF3(PSF11). The adjusting values of $\mathrm{E}_{\mathrm{g} 0}, \alpha, \beta$ and $\sigma$ are reported in table 3 . Note that for $\mathrm{T}=300 \mathrm{~K}$, all the excitons are delocalized due to the thermal excitation. Thus, the energy gap is more important in the PSF11 $\left(\mathrm{E}_{\text {gap }}=1.88 \mathrm{eV}\right)$ sample than in the PSF3 ( $\left.\mathrm{E}_{\text {gap }}=1.78 \mathrm{eV}\right)$ sample.

As temperature rises, the PL maximum band energy $\left[\mathrm{E}_{\mathrm{PL}}(\mathrm{T})\right]$ which is shown in Fig. 7.c. shift to lower energy side and each intensity decreases with increasing temperature. This behavior is caused by the decrease in the gap with the increase of the temperature. In fact there are two factors responsible for the variation of the energy gap with temperature.

First, because of thermal expansion the band structure and energy band gap decreases with increasing temperature. Second the effects of lattice vibrations and electron phonon interaction, which induce a link of the valence and conduction band and reflect the temperature dependence of the distribution of phonons. To describe this behavior there are several empirical laws (Varshni, Bose-Einstein, etc).

The most frequently used empirical relation for numerical fittings of $\operatorname{Eg}(T)$ was first suggested by Varshni $[37,38]$ and given as follows :

$$
E_{g}=E_{g 0}-\frac{\alpha T^{2}}{\beta+T}
$$

Where $E_{g 0}$ is the transition energy at $0 \mathrm{~K}, \alpha$ and $\beta$ are the Varshni coefficients.

Vina et al [35] proposed an empirical relation, which can be expressed as:

$$
E_{g}=E_{g 0}-\frac{\lambda}{e^{\theta / T}-1}
$$

Where the value of the energy gap at $0 \mathrm{~K}$ is $E_{g 0}, \lambda$ is an empirical constant and $\theta$ approximates the Debye temperatures [39].

The evolution of the peak energy of sample as a function of temperature simulated using the Bose-Einstein (Vina law) and the Varshni equation is presented in Fig. 7c. The adjustment parameters between $10 \mathrm{~K}$ and $300 \mathrm{~K}$ for the sample are listed in Table 3.

In our case, the Vina model is more accurate to the experiment data and reflects the behavior at low and high temperature revealing the domination of the electron-phonon interactions.

\subsubsection{PL intensity study}

In Fig. 8, we display the normalized integrated PL intensity for PSF3, PSFe11 and the PSF22 samples as a function of temperature. When the temperature increases, we observe a monotonic intensity decrease of the PSF22 sample while the PSF3 and PSF11 samples 
witnessed two intensity decrease regions. In the low temperature region, the increasing PL intensity indicates that more carriers were captured by the local potential fluctuations. At higher temperatures, the carrier thermal escape from the local potential fluctuations becomes dominant, leading to a decrease in the PL intensity. Therefore, the competition between these two processes will exhibit a maximum PL intensity at a certain temperature $\mathrm{T}_{\mathrm{M}}$. It can be seen from Fig. 8 that these samples exhibit different maximum intensity temperatures. The confinement energies for PSF11 $(\mathrm{E}=1.88 \mathrm{eV})$ are typically shallower than for SPF3 samples $(E=1.78 \mathrm{eV})$, therefore, carriers in the PSF11 will thermally escape from the local potential fluctuations at lower temperatures, which will result in a lower $\mathrm{T}_{M}\left(\mathrm{~T}_{\mathrm{M}}=140 \mathrm{~K}\right)$ for the PSF11 sample.

At a low temperature of $10 \mathrm{~K}$, carriers in the PSF3 sample are randomly distributed among the potential minima (Fig. 8). As the temperature increases from $10 \mathrm{~K}$ up to $\mathrm{T} \approx 120 \mathrm{~K}$, weakly localized carriers are thermally activated and relax down into other strongly localized states and reach a saturated redistribution, resulting in the initial redshift of the peak energy and a decrease of PL intensity. In the 120-160 K interval, increasing temperature enable carriers to achieve the thermal equilibrium with the lattice and to occupy higher-energy levels of the localized states, resulting thus in the blueshift of the peak energy toward the free-exciton ground state up to $\mathrm{T} \approx 170 \mathrm{~K}$ and an increase of the IPL. With a higher increase in temperature, the thermal energy prevents the exciton localization and the line shape of the PL spectrum becomes a characteristic line shape of the delocalized exciton recombination resulting in a decrease of the PL intensity. In fact there are two kinds of carrier transfer processes: i- tunneling transfer $[40,41]$ which occurs when the carrier energy is lower than the barrier height. ii- classical activation transfer [40] due to thermal activation across the barrier which is negligible at the low temperatures. Due to the effect of the different carrier injection processes the emission intensity of samples could be changed. Increasing temperature could enhance the tunneling rate. However, the thermal dissociation of excitons increases with temperature promoting the escape of excitons from QD to QW.

The integrated PL intensity of samples as a function of reciprocal temperature is displayed in fig 9. On the basis of the excitons - tunneling and dissociation model, the temperature dependence of the PL intensity from the QD and QW can be expressed by the equation bellow [42]:

$$
I=\frac{A}{\exp \left(\frac{E_{1}}{K_{B T}}\right)-1}+\frac{B}{1+\exp \left(\frac{-E_{2}}{K_{B T}}\right)}+D
$$


The first and second terms of equation represent the excitons tunneling and the thermal dissociation respectively. $\mathrm{A}, \mathrm{B}, \mathrm{C}$ and $\mathrm{D}$ are constants, $\mathrm{E}_{1}$ is the LO-phonon energy of tunneling assistance, $\mathrm{E}_{2}$ is an activation energy of thermal dissociation and $\mathrm{K}_{\mathrm{B}}$ is Boltzmann's constant. By fitting the experimental data for the PSF3 (PSF11) samples (fig9), we obtain $\mathrm{A}<0, \mathrm{E} 1=15.8 \mathrm{meV}\left(\mathrm{E}_{1}=12.83 \mathrm{meV}\right)$ and $\mathrm{E}_{2}=16.8 \mathrm{meV}\left(\mathrm{E}_{2}=13.45 \mathrm{meV}\right)$.

It is easy to find that the contribution of the exciton tunneling to the emission from the PSF3 (PSF11) samples is negative, which implies that the exciton tunneling can reduce the emission.

By fitting the experimental data for PSF22, we obtain $E_{1}=66 \mathrm{meV}$ and $\mathrm{E}_{2}=68 \mathrm{meV}$. The value of $E_{1}$ is close to the LO-phonon energy of silicon barrier $(63 \mathrm{meV})$. However the value of activation energy is much larger than that of PSF3 and PSF11 and the binding energy of the exciton in the Si bulk (the exciton binding of silicon=15meV). Therefore, in a nanoparticle exciton cannot be broken up by thermal phonons, thus, the higher activation energy possibly associated to the exciton tunneling process [43].

\section{Conclusions}

In summary, we have studied PL of PSF at different temperatures and current densities. According to this study, we observed anomalous emission behavior due to the presence of strong potential fluctuations in the material, which could be at the origin of the Sshape of the PL band temperature dependence. Typical surface morphology is observed in PSF. The observed PL behavior was associated to the competition between localized exciton and free exciton recombination. The PL is explained using quantum confinement model which well described the typical observed morphology of PSF surface. The increase of electro-deposition current density promotes the transformation of spherical crystallites to cylindrical ones and induced an important fluctuating potential. Temperature dependent PL of SPF3 and SPF11 samples show the thermal quenching with increasing temperature. PL peak energy shows S-shaped behavior, i.e., a redshift-blueshift-redshift with increasing temperature. This S-shaped behavior of PL peak energy can be explained by localized exciton model. At low temperature, recombination occurs due to the localized states. At high temperature, a blueshift occurs due to carriers escape into the LE states. With further increase of temperature, the band gap evolution follows the Bose-Einstein model. The S-shaped temperature dependence was not observed for the rest of samples.

\section{Acknowledgements}

We would like to acknowledge to Ahmed Souissi and Radhouane Chtourou from CNRTe Borj Cedria for PL measurements at different temperatures. The authors would like to thank also Zeineb Dkhili for her correction of English language. 


\section{References}

[1] A. G. Cullis and L. T. Canham, Nature, 353 (1991) 335-337.

[2] P. Menna, S. Tsuo, L. Canham. Ed. INSPEC, London, UK, (1997).

[3] P.Vitanov, E. Goranova, V. Stavrov, P.Ivanov, P. K. Singh, . Solar Energy Mater. Solar Cell Solar Energy Mater. Solar Cell. 93 (2009), 297-300.

[4] F. Otoi, K. Anzai, H. Kitabayashi, K. Uchiho, Y. Mizokami, J. Electrochem. Soc.131 (1984) 319.

[5] C. C. Chang, L. C. Chen, Mater. Lett. 32 (1997) 287-290.

[6] M.A. Rocchia, E. Garrone, F. Geobaldo, L. Boarino, M.J. Sailor, Phys. Stat. Sol. (A) 197 (2003) 365-369.

[7] E. Massera, I. Nasti, L. Quercia, I. Rea, G. Di Francia, Sens. Actuators, B 102 (2004) 195-197.

[8] D. J. Wolford, B. A. Scott, J. A. Remier and J. A. Bradley, Phisica .B, 117-118 (1983) 920-922.

[9] L. T. Canham, M. R. Houlton, W. Y. Leong, C. Pickering, and J. M. Keen, J. Appl. Phys. 70 (1991) 422-431.

[10] M. A. Tischler, R. T. Collins, J. H. Stathis, and J. C. Tsang, Appl. Phys. Lett. 60 (1991) 639-641.

[11] J. Sun, X. Han, X. W. Du, Y. W.Lu. Materials Letters, 59 (2005) 3135-3137.

[12] Y. H. Zhang, X. J. Li, L. Zheng, Q. W. Chen. Phys. Rev. Lett. 81 (1998) 1710-1713.

[13] D. Zhu, L. Zheng, X. Li, Y. H. Zhang, Appl. Phys. 86 (1999) 692-694.

[14] Q. W. Chen, X. Li, Y. Zhang. Chemical physics. 343 (2001)507-512.

[15] H. S. Mavi, B. G. Rasheed, A. K. Shukla, R. K. Soni, S. C. Abbi. Mat. scien and Eng. B 97 (2003) 239-244.

[16] R. Herino, Impregnation of porous silicon in: Properties of Porous Silicon, Ed. L. T. Canham, INSPEC, London (1997).

[17] F. Ronkel, J.W. Schultze, R. Arensfischer. Thin Solid Films, 276 (1996) 40-43.

[18] J. Rouquette, J.M. Pauthe, M. Ramonda, T. Taliercio, Gil B. Gil, K.P. O’Donnell, MRS Proceedings .737 (2003) 461-467.

[19] J. Rouquette, M. Pauthe, M. Ramonda, M. Vladimirova, B. Gil. Jpn. J. Appl. Phys. 42 (2003) 619-621.

[20] C. H. Fang, E. Foca, S. Xu, J. Carstensen, H. Föll. J. Electrochem. Soc. 154(2007) 4549. 
[21] K. Fukami, K. Kobayashi, T. Matsumoto, Y.L. Kawamura, T. Sakka, and Y.H. Ogata, J. Electrochem. Soc., 155(2008) 443-448.

[22] M. Rahmani, A.Moadhen, M-A.Zaibi, H. Elhouichet, M. Oueslati, J of Lumin., 128(2008)1763-1766.

[23] D. T. J. Ee, C. K. Sheng, M.I.N. Isa. The Malaysian Journal of Analytical Sciences, 15(2011) 227-231.

[24] B. Gelloz, Appl. Surf. Scien. 108 (1997) 449-454.

[25] A.G. Cullis, L.T. Canham, O.D. Dosser. Mater. Res. Soc. Symp. 256 (1992) 7.

[26] I. Berbezier, A. Halimaoui, J. Appl. Phys., 74 (1993) 5421-5425.

[27] B. Bessais, H. Ezzaouia, H. Elhouichet, M. Oueslati, R. Bennaceur, Semicond. Sci. Technol. 11 (1996) 1815-1820.

[28] H. Elhouichet, B. Bessais, O. Ben Younes, H. Ezzaouia,M. Oueslati, Thin Solid Films, 304 (1997) 358-364.

[29] C. Delerue, G. Allan, M. Lannoo, Phys. Rev. B, 48 (1993)11024-11036.

[30] I. Dirnstorfer, Mt. Wagner, D. M. Hofmann, M. D. Lampert, F. Karg, B. K. Meyer. Phys. Status Solidi. A. 168 (1998) 163-175.

[31] Y.H. Cho, T. J. Schmidtt, S. Bidnyk, , J. J. Song, S. Keller, U. K. Mishra, S. P. Denbaars. Physical Rev. B 61 (2000)7571.

[32] Y.H. Cho, G. H. Gainer, A. J. Fischer, J. J. Song, S. Keller, U. K. Mishra, S. P. Denbaars Appl. Phys. Letters 7 (1998)1370-1372.

[33] J. Bai, T. Wahg, S. Sakai. J. Appl. Phys. 88 (2000)4729-4733.

[34] S. A. Lourenco, I. F. L. Dias, J. L. Duarte, E. Laureto, V. M. Aquino, and J. C. Harmand. Brazilian Journal of Physics; 37 (2007)1212-1219.

[35] L. Vina, S. Logothetidis, M. Cardona. Phys. Rev. B. 30(1984) 1979-1991.

[36] P.G. Eliseev, P. Perlin, J. Lee, M. Osinski, Appl. Phys. Lett.71 (1997) 569-571.

[37] Y. P. Varshni. Physica (Utrecht), 34 (1967) 149-154.

[38] K. P. O’ Donnell, X. Chen. Appl. Phys. Lett. 58(1991)2914.

[39] M. B. Panish, H.C. Casey. Phys. Rev. 40 (1969) 163.

[40] D. Zhao, B.Li, C.Wu, Y. Lu, D. Shen, J. Zhang, X. Fan. J. Lum. 304(2006)119-120.

[41] G.E. Weng, B. P. Zhang, M.M .Liang, X. Q. Lv, J. Y. Zhang, L.Y. Ying, Z. R. Qiu, H. Yaguchi, S. Kuboya, K. Onabe, S. Q. Chen, H. Akiyama. Materials Letters,06 (2013)02. 
[42] G. Yu, X. W. Fan , J. Y. Zhang, Z. H. Zheng , B. J. Yang, X. Zhao , D. Z. Shen, X. G. Kong. J. Phys. D: Appl. Phys. 32(1999)1506-1510.

[43] J. Hua, Z. Li-Gong, Z. Zhu-hong, A. Nan, L. You- Ming, Z Ji-Ying, F. Xi-Wu, S. DeZhen. Chin. Phys. Lett. 22(2005)1518-1521.

\section{Figures and tables captions}

Figure 1: $\quad$ SEM of PS as prepared (A), PSF3 $\left[\mathrm{J}=3 \mu \mathrm{A} / \mathrm{cm}^{2}\right](\mathrm{B}), \operatorname{PSF} 22\left[\mathrm{~J}=22 \mu \mathrm{A} / \mathrm{cm}^{2}\right]$ (C) and PSF32 $\left[\mathrm{J}=32 \mu \mathrm{A} / \mathrm{cm}^{2}\right](\mathrm{D})$.

Figure 2: $\quad$ SEM of cross-section of PS, PSF3, PSF22 and PSF32 structures for $J=0 \mu \mathrm{A} / \mathrm{cm}^{2}$ (A), $\mathrm{J}=3 \mu \mathrm{A} / \mathrm{cm}^{2}(\mathrm{~B}), \mathrm{J}=22 \mu \mathrm{A} / \mathrm{cm}^{2}(\mathrm{C})$ and $\mathrm{J}=32 \mu \mathrm{A} / \mathrm{cm}^{2}(\mathrm{D})$ respectively.

Figure 3: Variation of $\mathrm{Fe}$ atomic percent as a function of the deep in the porous layer of SPF3.

Figure 4: $\quad$ PL spectra of PS and PSF samples for different electro-deposition current.

Figure 5: Theoretically calculated PL contributions of dots (QD) and wires (QW) in the experiment PL spectra (full curve) at $\mathrm{T}=300 \mathrm{~K}$ for different electro-deposition current density $\mathrm{J}_{\mathrm{c}}$ : a- $\mathrm{J}_{\mathrm{c}}=0 \mu \mathrm{A} / \mathrm{cm}^{2}$ (PS), b- $\mathrm{J}_{\mathrm{c}}=22 \mu \mathrm{A} / \mathrm{cm}^{2}$ (PSF22), c- $\mathrm{J}_{\mathrm{c}}=32 \mu \mathrm{A} / \mathrm{cm}^{2}$ (PSF32).

Figure 6: Adjusted diameters of dots (continuous line) and wires (dashed line) of samples etched at different electro-deposition current intensities.

Figure 7: $\quad$ PL band energy $\left(\mathrm{E}_{\mathrm{PL}}\right)$ as a function of temperature of samples PSF3, PSF11 and PSF22.The solid curve is calculated using the Gaussian band-tail model described in Ref [36] for samples of PSF3 and PSF11. Note that Bose-Einstein model is a very good agreement with experimental data for sample PSF22.

Figure 8: The temperature dependence of the normalized integrated PL intensities for samples PSF3, PSF11 and PSF22.

Figure 9: Integrated PL intensities as a function of the reciprocal temperature for PSF3, PSF11 and PSF22 samples.

Table 1: $\quad$ Optimized fitting parameters giving the theoretical curves shown in Fig. 5.

Table 2: $\quad$ Optimized fitting parameters giving the theoretical curves shown in figure 7.

Table 3: Adjustment Parameter for Varshni relation and the Bose-Einstein statistics (Vina law). 
Figure 1

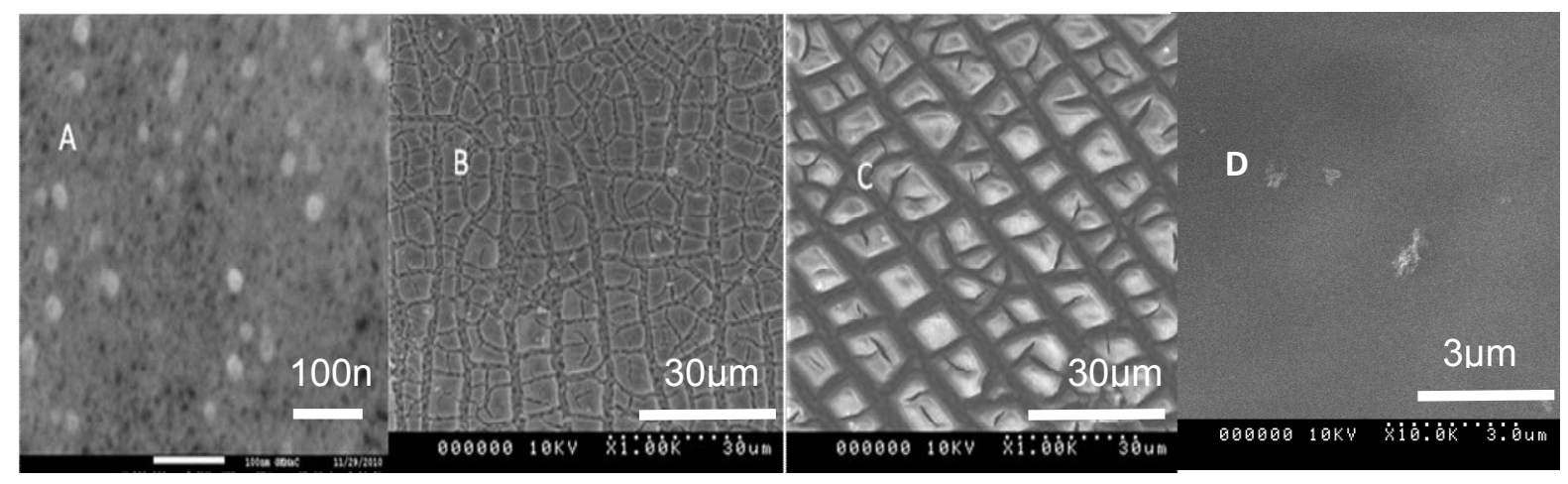


Figure 2 


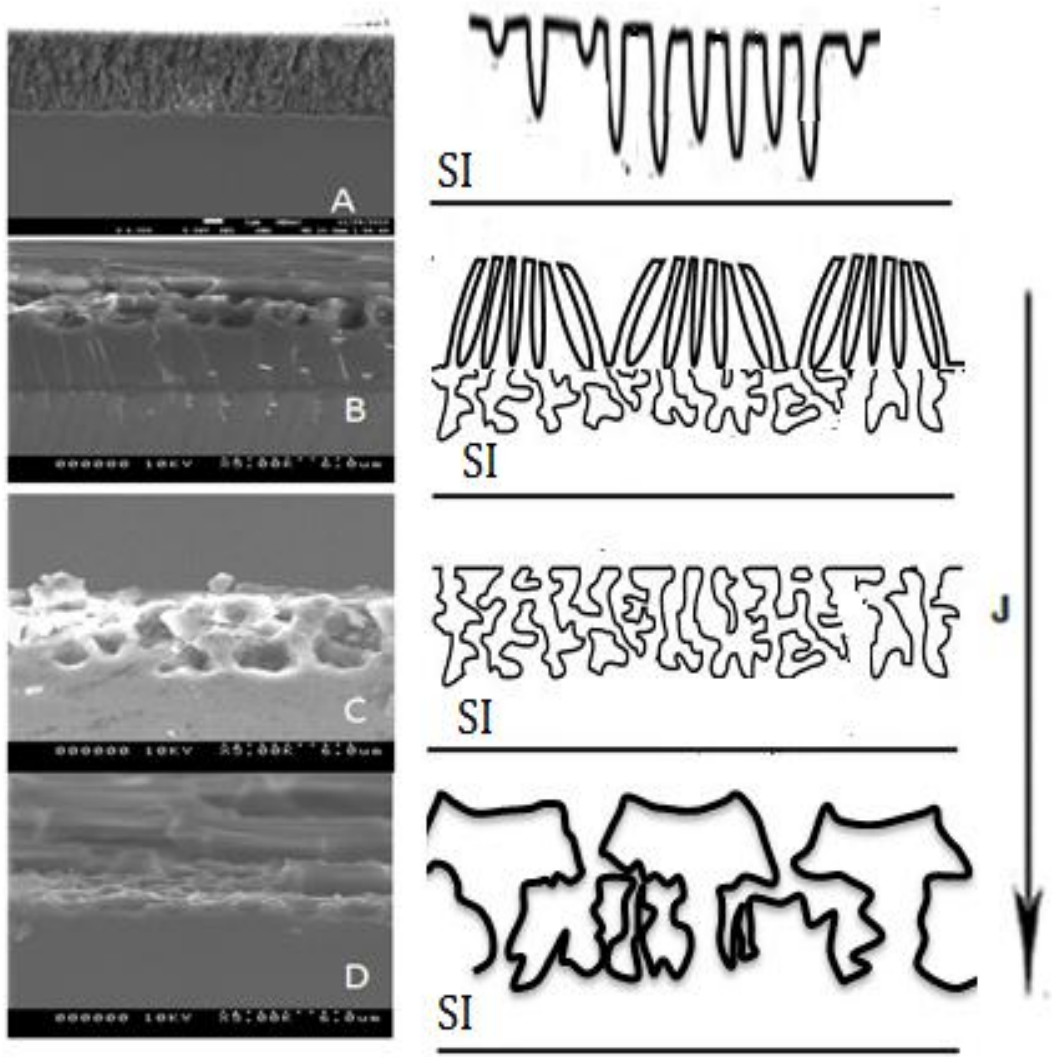

Figure 3 


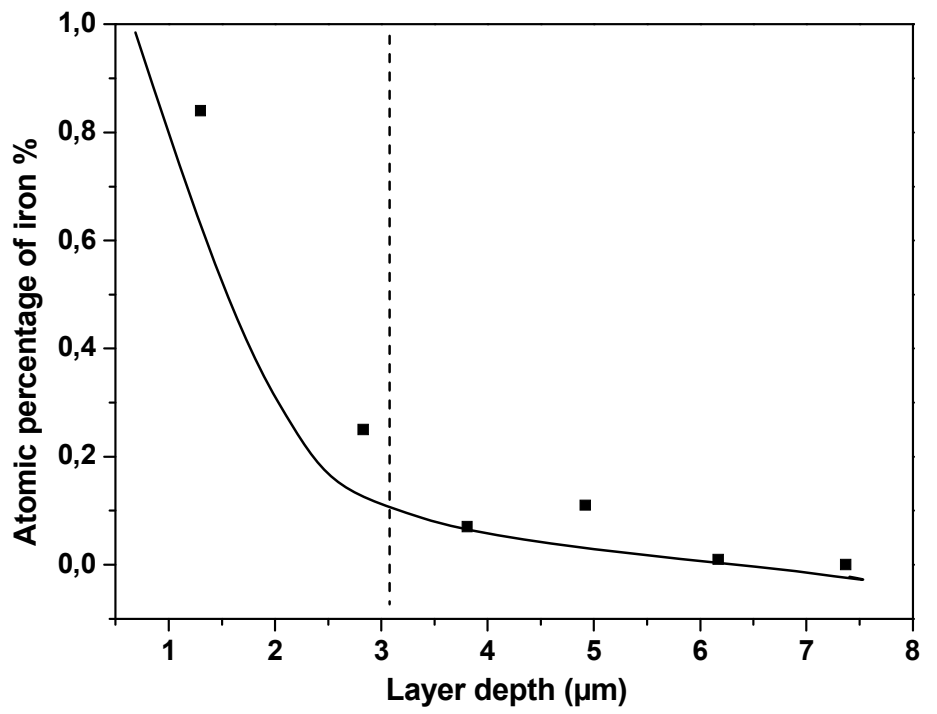


Figure 4

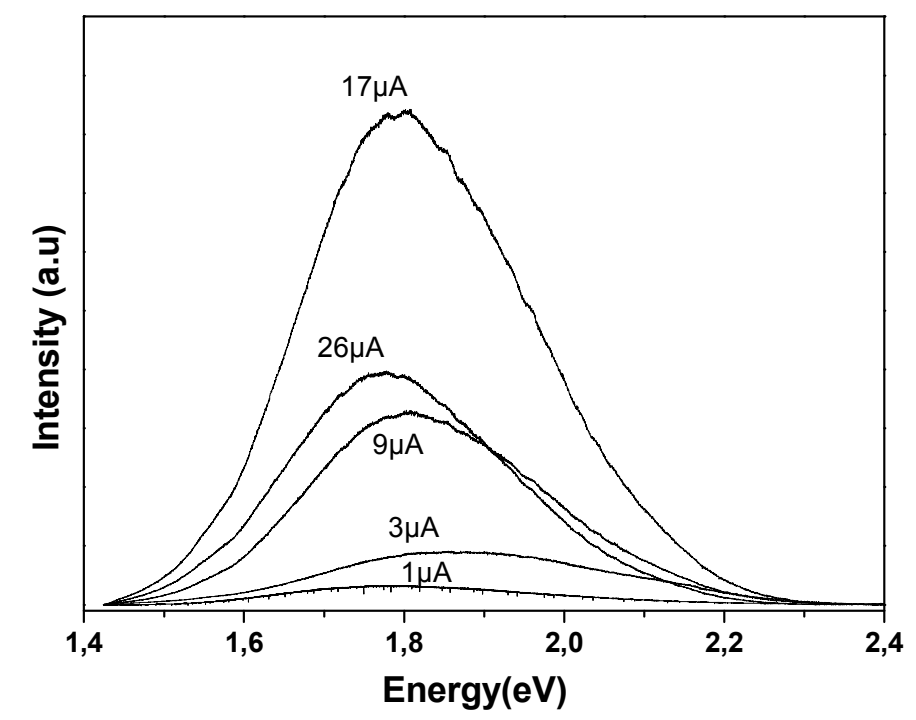


Figure 5

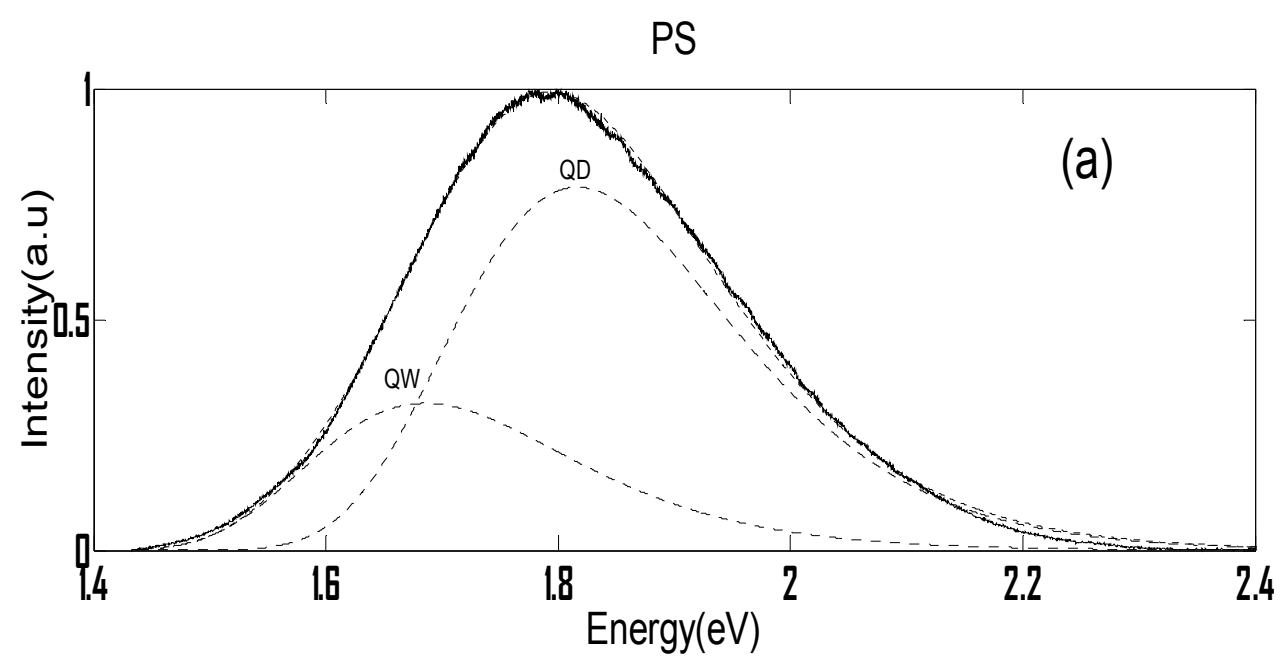



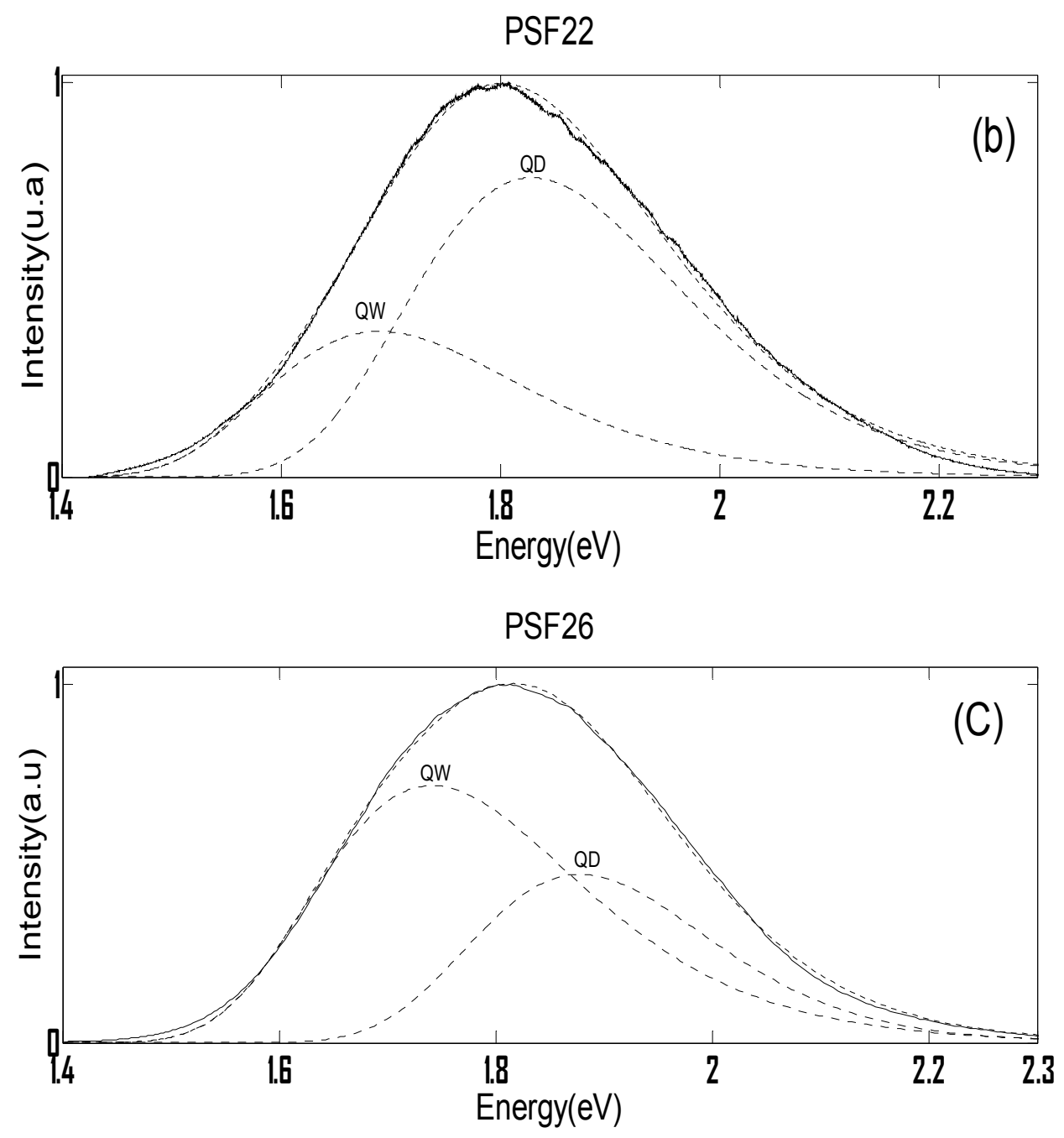

Figure 6 


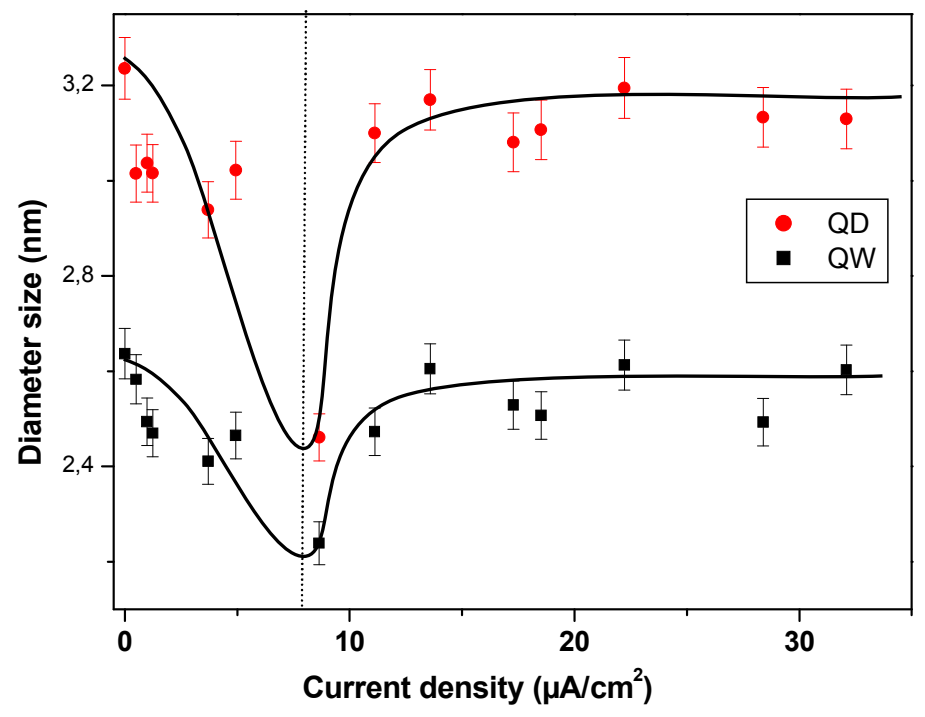


Figure 7

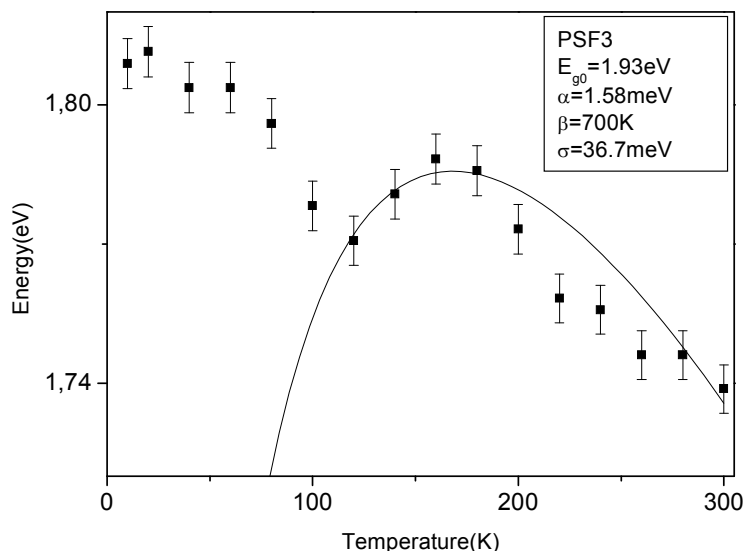

(a)

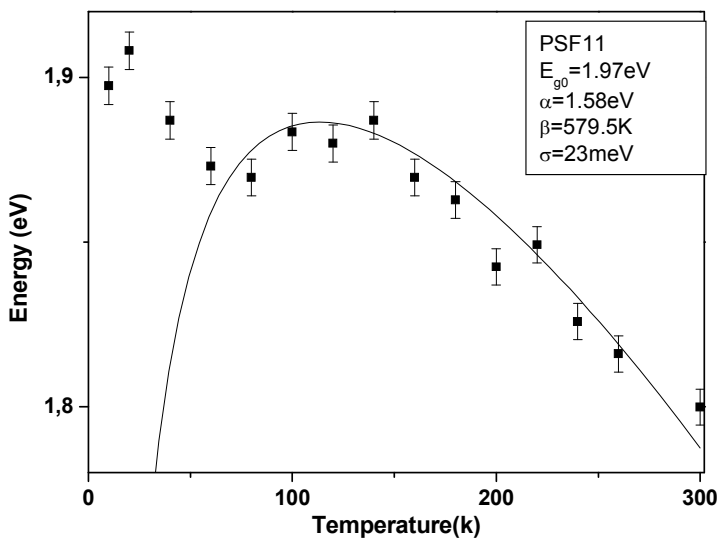

(b)

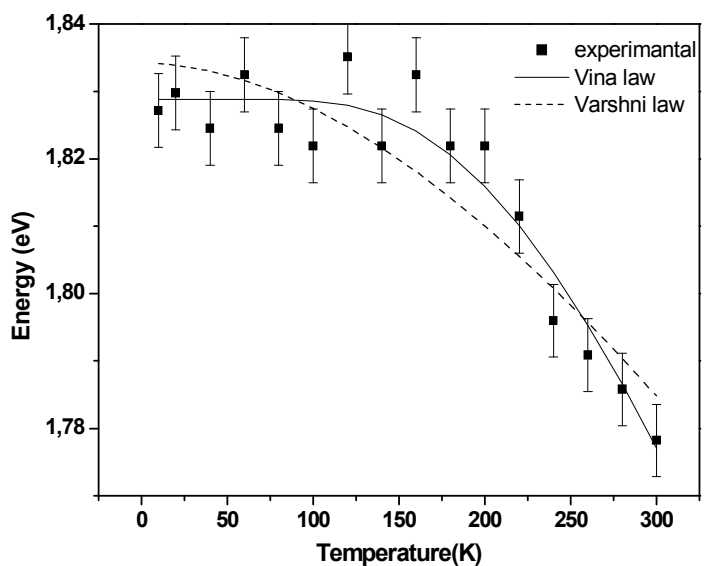

(c)

Figure 8 


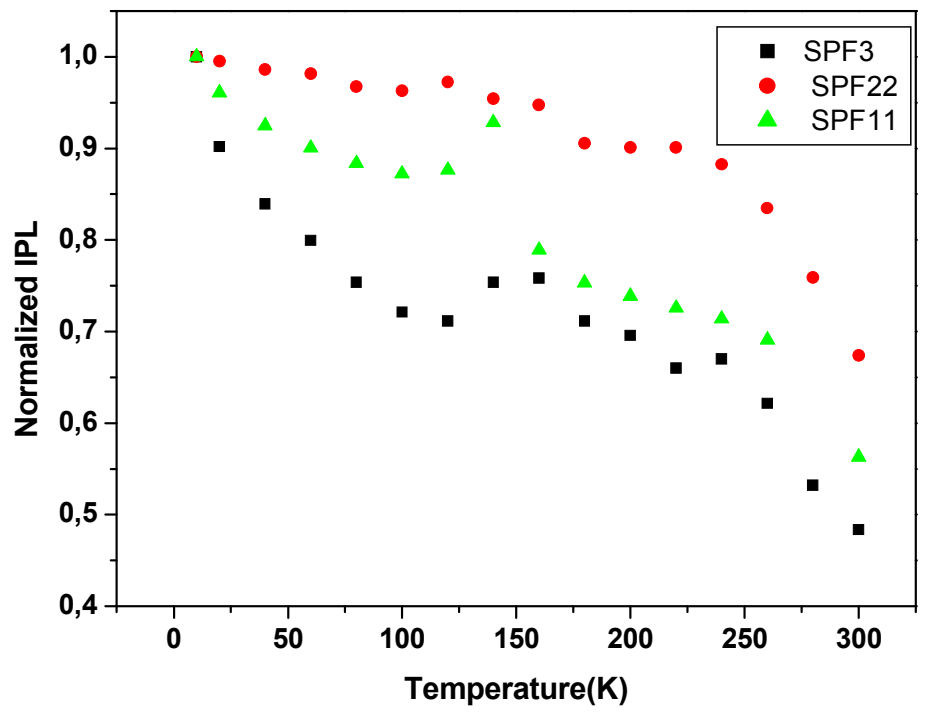


Figure 9 

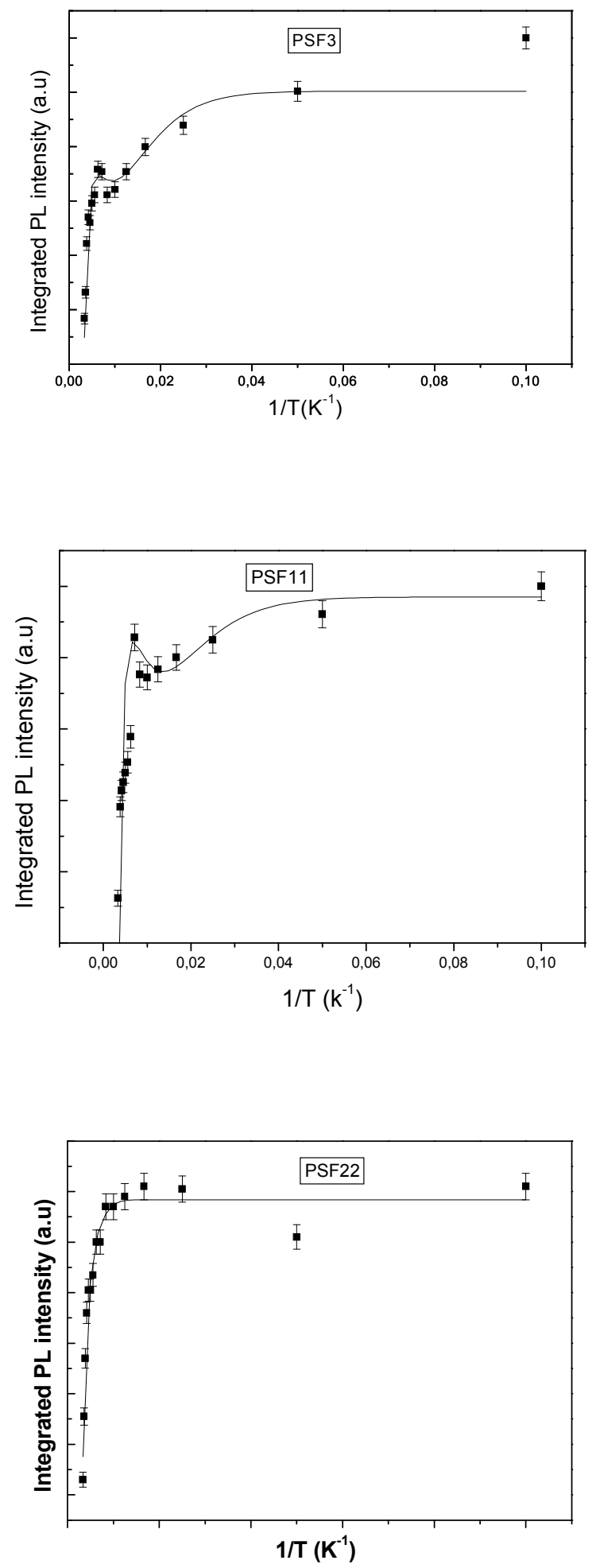

Figures caption

Figure 1: $\quad$ SEM of PS as prepared (A), PSF3 $\left[\mathrm{J}=3 \mu \mathrm{A} / \mathrm{cm}^{2}\right]$ (B), PSF22 $\left[\mathrm{J}=22 \mu \mathrm{A} / \mathrm{cm}^{2}\right]$ (C) and PSF32 $\left[\mathrm{J}=32 \mu \mathrm{A} / \mathrm{cm}^{2}\right](\mathrm{D})$. 
Figure 2: $\quad$ SEM of cross-section of PS, PSF3, PSF22 and PSF32 structures for $\mathrm{J}=0 \mu \mathrm{A} / \mathrm{cm}^{2}$ (A), $\mathrm{J}=3 \mu \mathrm{A} / \mathrm{cm}^{2}(\mathrm{~B}), \mathrm{J}=22 \mu \mathrm{A} / \mathrm{cm}^{2}(\mathrm{C})$ and $\mathrm{J}=32 \mu \mathrm{A} / \mathrm{cm}^{2}(\mathrm{D})$ respectively.

Figure 3: $\quad$ Variation of Fe atomic percent as a function of the deep in the porous layer of SPF3.

Figure 4: $\quad$ PL spectra of PS and PSF samples for different electro-deposition current.

Figure 5: Theoretically calculated PL contributions of dots (QD) and wires (QW) in the experiment PL spectra (full curve) at $\mathrm{T}=300 \mathrm{~K}$ for different electro-deposition current density $\mathrm{J}_{\mathrm{c}}$ : a- $\mathrm{J}_{\mathrm{c}}=0 \mu \mathrm{A} / \mathrm{cm}^{2}$ (PS), b- $\mathrm{J}_{\mathrm{c}}=22 \mu \mathrm{A} / \mathrm{cm}^{2}$ (PSF22), c- $\mathrm{J}_{\mathrm{c}}=32 \mu \mathrm{A} / \mathrm{cm}^{2}$ (PSF32).

Figure 6: $\quad$ Adjusted diameters of dots (continuous line) and wires (dashed line) of samples etched at different electro-deposition current intensities.

Figure 7: $\quad$ PL band energy $\left(\mathrm{E}_{\mathrm{PL}}\right)$ as a function of temperature of samples PSF3, PSF11 and PSF22.The solid curve is calculated using the Gaussian band-tail model described in Ref [36] for samples of PSF3 and PSF11. Note that Bose-Einstein model is a very good agreement with experimental data for sample PSF22.

Figure 8: The temperature dependence of the normalized integrated PL intensities for samples PSF3, PSF11 and PSF22.

Figure 9: Integrated PL intensities as a function of the reciprocal temperature for PSF3, PSF11 and PSF22 samples.

Table 1

\begin{tabular}{|c|c|c|c|c|c|c|}
\hline Samples & $\mathrm{J}_{\mathrm{c}}\left(\mu \mathrm{A} / \mathrm{cm}^{2}\right)$ & $\chi_{D}(\%)$ & $\chi_{W}(\%)$ & $\bar{c}$ & $\mathrm{~d}_{\mathrm{OW}}(\mathrm{nm})$ & $I_{P L}(Q W) / I_{P L}(Q D)$ \\
\hline PS & - & 0.79 & 0.21 & 3.2 & 2.7 & 0.4 \\
\hline SPF11 & 11 & 0.42 & 0.57 & 3.1 & 2.5 & 2.04 \\
\hline SPF22 & 22 & 0.77 & 0.23 & 3.2 & 2.6 & 0.49 \\
\hline SPF28 & 28 & 0.50 & 0.50 & 3.1 & 2.5 & 1.52 \\
\hline SPF32 & 32 & 0.71 & 0.23 & 3.1 & 2.6 & 0.49 \\
\hline
\end{tabular}


Table 2

\begin{tabular}{|lccccc|}
\hline Samples & $J_{c}\left(\mu \mathrm{A} / \mathrm{cm}^{2}\right)$ & $E_{g 0}$ & $\alpha$ & $\beta$ & $\sigma$ \\
\hline SPF3 & 3 & 1.93 & 1.58 & 700 & 36.7 \\
SPF11 & 11 & 1.97 & 1.58 & 579.5 & 23 \\
\hline
\end{tabular}

Table 3

\begin{tabular}{|c|c|}
\hline Varshni law & Vina law \\
\hline \multicolumn{2}{|c|}{ Pic position : $1.8216 \mathrm{eV}$} \\
\hline $\mathrm{E}_{\mathrm{g} 0}=1.8342 \mathrm{eV}$ & $\mathrm{E}_{\mathrm{g} 0}=1.8288 \mathrm{eV}$ \\
\hline$\sigma=0.6 \mathrm{meV} / \mathrm{K}$ & $\lambda=0.693 \mathrm{eV}$ \\
\hline$\beta=799 \mathrm{~K}$ & $\theta=799.8 \mathrm{~K}$ \\
\hline
\end{tabular}

\section{Tables caption}

Table 1: $\quad$ Optimized fitting parameters giving the theoretical curves shown in Fig. 5.

Table 2: $\quad$ Optimized fitting parameters giving the theoretical curves shown in figure 7.

Table 3: $\quad$ Adjustment Parameter for Varshni relation and the Bose-Einstein statistics (Vina law). 